\title{
CORRIGENDUM
}

\section{Claudin-1 induces epithelial-mesenchymal transition through activation of the c-Abl-ERK signaling pathway in human liver cells}

Y Suh, C-H Yoon, R-K Kim, E-J Lim, YS Oh, S-G Hwang, S An, G Yoon, MC Gye, J-M Yi, M-J Kim and S-J Lee

Oncogene (2017) 36, 1167-1168; doi:10.1038/onc.2016.294; published online 14 November 2016

Correction to: Oncogene (2013) 32, 4873-4882; doi:10.1038/ onc.2012.505; published online 19 November 2012

We were recently made aware of concerns regarding discontinuities and duplications of portions of Figures 3 and 5 of this publication, which arose from errors in rearranging the blot images between figures prior to publication. We sincerely apologize for a lack of clarity and errors involving these figures. Below are revised images and explanatory text.

1. Duplication of CLD1 bands in Figure 1a and Figure $3 a$. Because Chang cell clones ( $C$ no. 1, C no. 11 and $C$ no. 13) stably overexpress CLD1 as shown in Figure 1a, we deleted the western immunoblotting band for CLD1 in Figure 3a.
2. Duplication of $\boldsymbol{\beta}$-actin in Figures $5 \mathrm{~g}$ and $\mathrm{h}$. We performed the experiment again and replaced the data in Figure $5 \mathrm{~h}$.

3. Duplication of $\boldsymbol{\beta}$-actin in Figures $5 \mathrm{a}$ and e. We performed the experiment again and replaced the data in Figure $5 \mathrm{e}$.

The updated figures do not change the interpretation of the data or the stated conclusions in the original Oncogene manuscript.

We apologize to readers for any inconvenience this may have caused.

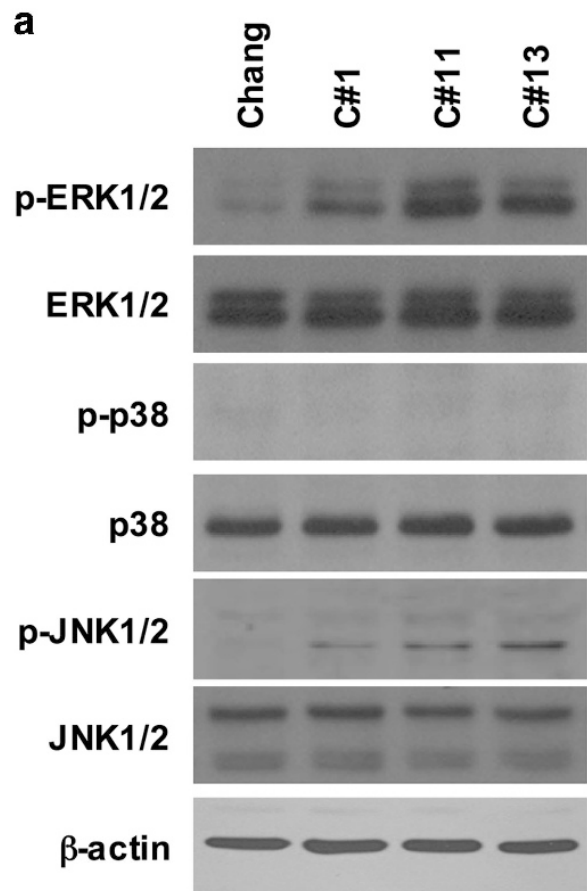

Figure 3. 
e

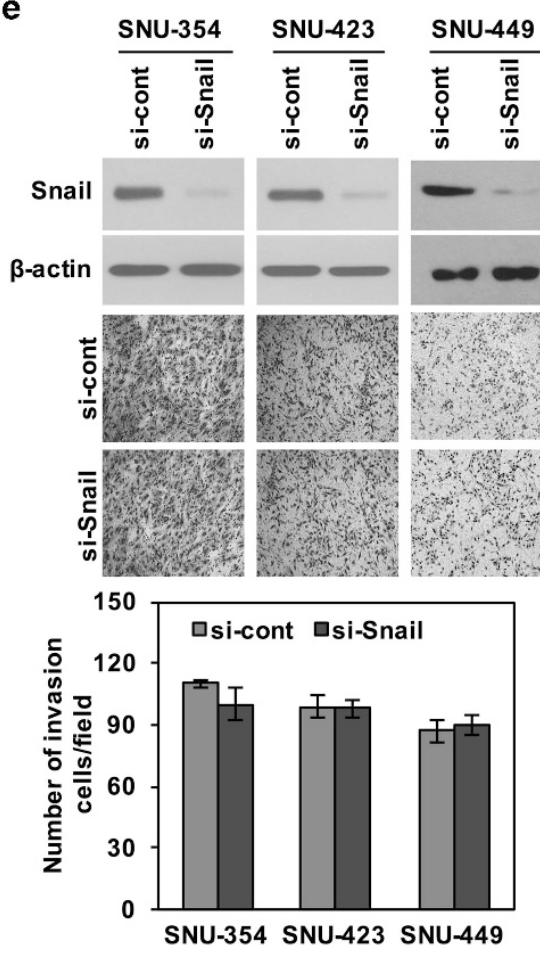

h

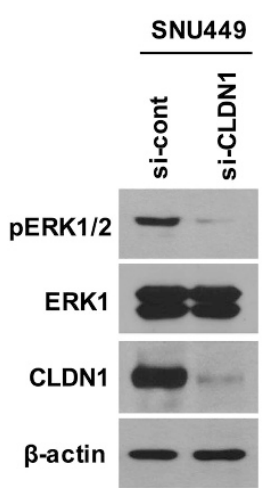

Figure 5. 